Metodologia (Methodology)

\author{
A numerical criterion for assessing \\ the discriminatory/aggregative potential of a taxonomic \\ character with a Fortran 90 program for calculations \\ Um critério numérico para avaliar \\ o potencial discriminatório/agregativo \\ de um caráter taxonômico com um programa \\ Fortran 90 para cálculos
}

Joaquim Carlos Sena Maia ${ }^{1}$

One of the steps in a taxonomic study concerns the identification and design of groups that are outlined (OTU's Taxonomic Operational Units) which need to be analyzed by taxonomists (see SNEaTH \& SoKaL, 1973).

In all steps, two basic types of characters are taken into account: those that add simpler units and form hierarchically superior units, usually by similarities (e.g., gathering of related species to form a taxomic group) and the ones discriminating different groups.

The basic intention of this work is to present an alternative method for, using numerical criteria to allow an assessment of the discriminatory or aggregative potential of a taxonomic character.

\title{
MATERIALAND METHODS
}

Six species of the genus Plebeia (Hymenoptera, Apidae) were used, namely: Plebeia juliani, Plebeia droryana, Plebeia emerina, Plebeia meridioanalis, Plebeia remota and Plebeia saiqui, whose data were used in the author's master's thesis (MAIA, 2017), in the creation of an evaluation criterion for the interspecific structure of the Plebeia using

${ }^{1}$ Professor Adjunto (Aposentado) do Departamento de Estatística da UFPR. E-mail: jcsenamaia@gmail.com. 
qualitative and quantitative variables. In this case, data were submitted to analysis of variance (MAIA, 2017).

To exemplify the method now proposed, we selected four morphological characters (punctuation of propodium, labrum color, pronotum color and scape color) with their respective status, such as, for example, "yellow" and "black" status for the character color of the scape. Of 17 attributs used in the thesis (MAIA, 2017) we choised four to demonstrate the functioning of the numerical model.

Each status of a given character works with a grouping criterion that can include one or more species. Thus, considering the color of the labrum, the status "white" is present in $P$. juliani and $P$. meridionalis, the "yellow" status includes $P$. droryana and $P$. emerina, while the "black" status includes $P$. remota and $P$. saiqui species.

The number of species "housed" with each status is represented by the letter K. Thus, in the analysis of the character color of the labrum, we have the value of $\mathrm{K}=2$ (two species) in each of the statuses (white, yellow and black). As three groups were formed (each group corresponding to a status) therefore $\mathrm{n}=3$.

Then we calculate the product of $\mathrm{K}$ values (multiply $\mathrm{K}_{1} \times \mathrm{K}_{2} \mathrm{x} \ldots \mathrm{x}$ $\mathrm{K}_{\mathrm{n}}$ ) to obtain the value of $\mathrm{P}$. Extracting the root of order $\mathrm{n}$ of the value of $\mathrm{P}$ we obtain the geometric mean $\mathrm{G}$ of the product under consideration. For $\mathrm{P}$ is the producer.

$$
G=\sqrt[n]{V^{\prime}}=\sqrt[3]{2 \times 2 \times 2}=2
$$

The value found (2) is geometric mean of the coefficients that indicate the number of species in each group (or status).

The geometric mean is the statistical quantity that best describes, in this methodology, the internal structure species distribution in relation to the status of the analyzed characters (see PIZANI ET AL. 1966).

To facilitate the interpretation of the results, we adopted the criterion of making the results oscillate between 0 (zero) and $5(0<=\mathrm{D}<=5)$, calculating the value of $\mathrm{D}$ (degree of discrimination / aggregation) using the formula below, where $\mathrm{N}$ is equal to the number of species listed in this analysis.

$$
\mathrm{D}=5 \frac{\mathrm{N}-2 \mathrm{G}}{\mathrm{N}-2}
$$


where

$\mathrm{D}=$ degree of discrimination/aggregation of the analyzed character,

$\mathrm{N}=$ number of species (or other taxonomic unit),

$\mathrm{G}=$ geometric mean of the $\mathrm{K}$ values.

The value found $(\mathrm{G}=2)$ is the geometric mean of the product of the $\mathrm{K}$ values, that is, the value average of the coefficients that indicate the number of species in each group (or status). Using the data obtained on the previous page, we can calculate the value of the discriminatory potential/aggregative potential of the color taxonomic character of labrum:

$$
D=5-\frac{N-2 G}{N-2} \quad D=5 \frac{6-2(2)}{6-2}=2,5
$$

The interpretation of the $\mathrm{D}$ value can be done as follows:

$$
\begin{aligned}
& 0>=\mathrm{D}<=1-\text { very aggregative characters } \\
& 1<\mathrm{D}<=2 \text { - aggregative characters } \\
& 2<\mathrm{D}<=3 \text { - intermediate characters } \\
& 3<\mathrm{D}<=4 \text { - discriminatory characters } \\
& 4<\mathrm{D}<=5 \text { - very discriminatory characters }
\end{aligned}
$$

\section{RESULTS AND DISCUSSIONS}

\begin{tabular}{|c|c|c|c|c|c|}
\hline \multirow{2}{*}{$\begin{array}{l}\text { scapum } \\
\text { color }\end{array}$} & yellow & black & $P$ & & \\
\hline & D $\quad(k=1)$ & $J-M-E-R-S \quad \mid k=5$ & 5 & 2 & \\
\hline
\end{tabular}

We present in the Table 1 as an example of the calculations made for

\begin{tabular}{|c|c|c|c|c|c|c|c|c|c|}
\hline \multirow{3}{*}{$\begin{array}{l}\text { pronotum } \\
\text { color }\end{array}$} & \multirow[t]{2}{*}{$\begin{array}{l}\text { entirely } \\
\text { black }\end{array}$} & \multirow{2}{*}{\multicolumn{2}{|c|}{$\begin{array}{l}\text { incompl complete } \\
\text { yellow yellow } \\
\text { band } \\
\text { band }\end{array}$}} & \multirow{2}{*}{\multicolumn{2}{|c|}{$\begin{array}{l}\text { incompl } \\
\text { striae }\end{array}$}} & \multirow{2}{*}{$\begin{array}{l}\text { entirely } \\
\text { yellow }\end{array}$} & & & \\
\hline & & & & & & & $\mathrm{P}$ & G & D \\
\hline & $J \quad k=1)$ & M $\quad(k=1)$ & D $(k=1)$ & $\begin{array}{|ll|}E & (k=1) \\
5\end{array}$ & R $\quad(k=1)$ & $\begin{array}{ll}S & (k=1) \\
\end{array}$ & 1 & 1 & 5 \\
\hline
\end{tabular}

Table 1. Grouping formations.

\section{\begin{tabular}{|l|l|l|l|}
\hline Characters & Status/grouping formation & G & D \\
\hline
\end{tabular}}

\begin{tabular}{|l|c|c|c|c|c|}
\hline $\begin{array}{l}\text { Propodium } \\
\text { punctuation }\end{array}$ & rugous and reticulate & rugous just in the base & $\mathrm{P}$ & $\mathrm{G}$ & $\mathrm{D}$ \\
\cline { 2 - 7 } & $\mathrm{J}-\mathrm{M}-\mathrm{E} \quad(\mathrm{k}=3)$ & $\mathrm{D} \cdot \mathrm{R}-\mathrm{S} \quad(\mathrm{k}=3)$ & 9 & 3 & 0 \\
\hline
\end{tabular}

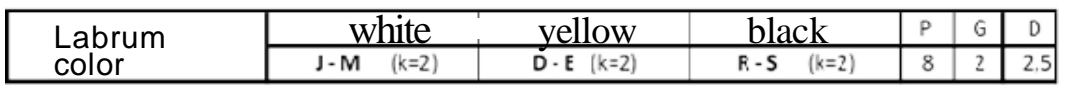


4 morphological characters of 6 species of the genus Plebeia. Each species is represented by the initial letter of respective specific name as follows: juliani: J, meridionalis: $\mathrm{M}$, droryana: D, emerina: E, remota: $\mathrm{R}$, saiqui: $\mathrm{S}$.

The Table 1 shows that the character "color of the pronotum" can be classified as "very discriminatory", as the value of D reaches the maximum possible, that is 5 . This value occurs when a taxonomic character has the property of being able to identify all the members of the analyzed taxon. The characters "color of the labrum" and "color of the scape" have an intermediate degree of discrimination and the D values are in the range between 2 and 3, more precisely 2.5 and 2.0.

The character "punctuation of the propodium" forms 2 groups of equal size indicating a minimum grade discriminatory (or maximum aggregation) because the value of $\mathrm{D}=0$ (zero). This occurs when we have a taxon formed by an even number of taxonomic units, with two statuses, and each status "hosts" exactly half of the members.

\section{CHARACTER WEIGHTING}

BuRTT (1964) warned that numerical taxonomy need not necessarily assign equal weights to all characters (isocratic classification). SNEARTH (1973) argues that the most recommended is to use equal weights for all characters. He agrees, however, that some complex characters are given weights in proportion to their complexity or informational content. MICHENER AND SoKAl (1957) conclude that, even if it is desirable, there is no rational way to determine character weights and, in practice, we should assign the same weight to all. According to them, when many characters are used, the similarity analyzes are only slightly affected by the weighting effects. FARRIS (1966) suggests that characters that vary little within populations are more reliable indicators of cladistic relationships than more variable characters and therefore should have greater weights. Goodman (1969) believes that a character should be inversely weighted to the variance within the taxonomic unit. In his studies of plant reproduction he found that variation can be largely attributed to environmental rather than genetic effects. Thus, genotypic differences can be better evaluated if highly variable characters are not emphasized by weighting criteria.

The calculation method we present in this work applies to the application of qualitative (or discrete) variables in which the different status of the analyzed characters can be coded by letters or numbers that identify them, without ranking them in taxonomic importance.

Thus, we discuss the possibility of using the values of D as a weight- 
Table 2. Weighting scale of $\mathrm{D}$ values emphasizing discriminative potential.

\begin{tabular}{ll}
\hline D value & Degree of discrimination \\
\hline $0<=\mathrm{D}<=1$ & Character very litttle discriminatory \\
$0<=\mathrm{D}<=2$ & Little discriminatory character \\
$0<=\mathrm{D}<=3$ & Moderate discriminatory character \\
$0<=\mathrm{D}<=4$ & Discriminatory character \\
$0<=\mathrm{D}<=5$ & Very discriminatory character \\
\hline
\end{tabular}

Table 3. Weighting scale of $\mathrm{D}^{\prime}$ values emphasizing aggregative potential.

\begin{tabular}{ll}
\hline D' value & Degree of aggregation \\
\hline $0<=\mathrm{D}^{\prime}<=1$ & Character very little aggregative \\
$0<=\mathrm{D}^{\prime}<=2$ & Little aggregative character \\
$0<=\mathrm{D}^{\prime}<=3$ & Moderate aggregative character \\
$0<=\mathrm{D}^{\prime}<=4$ & Aggregative character \\
$0<=\mathrm{D}^{\prime}<=5$ & Very aggregative character \\
\hline
\end{tabular}

ing factor, as it provides information that evidences the potential for aggregation or discrimination of a taxonomic character.

The calculation of $\mathrm{D}$ proposed in this article allows the creation of two weighting scales, emphasizing either the discriminative potential or the aggregative potential. If we intend to emphasize the discriminative potential, just calculate the values of $\mathrm{D}$ with the interpretation given in table 3 .

However, if the objective is to emphasize the aggregative potential of the character, we must calculate $\mathrm{D}^{\prime}$ complementary value of $\mathrm{D}$, as follows: $\mathrm{D}^{\prime}=5$ - $\mathrm{D}$. The interpretation of the values of $\mathrm{D}^{\prime}$ is shown in table 3 the capacity of aggregation or discrimination of a taxonomic character.

Some methods of numerical taxonomy can use weights that allow to differentiate the contribution of each character in the formation of a given 
taxonomic group. What we are discussing is the possibility of using the values of $\mathrm{D}$ as a weighting factor.

For calculus see the aplicative (see pág. 14).

\section{CONCLUSIONS}

1) In a taxonomic study, morphological, physiological, behavioral and ecological characters can be used.

2) Whatever the nature of the character used, as long as it receives an appropriate encoding, it can be analyzed as to its discriminative or aggregative potential for the configuration of a given undetermined taxon.

3) The contribution of character variations in each group allowing the individualization of each taxonomic unit can be expressed numerically through the methodology here presented.

4) The geometric mean can be an adequate way bo show taxonomic relationships.

5) The calculation of $D$ makes it possible to evaluate the informative potential of a taxonomic character in terms of discrimination or aggregation of taxonomic units.

6) It would be important to assess the relevance of using D as a weighting criterion in taxonomic studies.

Acknoledgements-To Prof. Graci Maria Fernandes de Oliveira (in memoriam) for suggestions that had contributed for the methodology formalization and to Dr. Sebastião Laroca for encouragement and suggestions.

\section{SUMMARY}

An alternative method of assessment of the discriminatory and aggregative potencials of a taxonomic character as contribuition to numerical taxonomy.

KEY WORD: numerical method; taxonomy; aggregative potencial; discriminatory character.

\section{SUMÁRIO}

Um método alternativo de avaliação dos potenciais discriminatórios e agregativos de caráter taxonômico, como contribuição à taxonomia numérica.

Palavras chave: método numérico; taxonomia; aggregativo; discriminatinatório.. 


\section{BIBLIOGRAPHY}

BurTt, B. L. 1964. Angiosperm taxonomy in practise. Phenetic an phylogenetic classification, pp 5-16. Sys. Ass. Pub. 6. 164 pp in Sneath P. H. A. \& R. R. Soka. 1973. Numerical Taxonomy - W. H. Freeman and Company, San Francisco, 573 pp.

FARRIS J. S. 1966. Estimation of conservatism of character by constancy with biological biological populations. Evolution 20:587591.

Goodman, M. M. 1969. Measuring evolutionary divergence. $J$. $J$. Genet. 44 (suppl. 1): 310-316 in Numerical Taxonomy

MaIA, J. C. S. 2017. Análise estatística interespecíficadas espécies paranaenses (Brasil) de Plebeia (Apidae, Meliponi). Acta Biol. Par., Curitiba, 46 (1-2): 39-58.

Michener, C. D. \& R. R. Sokal. 1957. A quantative approach to a problem in classification. Evolution 11: 130-162.

Pisani, J. F., J. S. Moure, B. Crestana, D. Aily, M. L. Lorenzetti. 1966. Análise estatística da estrutura interespecífica dos Bombus do Brasil(Hymenoptera, Apidae). Bol. Univ. Fed. Paraná. Zool. 8: 101-120.

Sneath, P. H. A. \& R. R. Sokal. 1973. Numerical Taxonomy, F. H. Freeman and Company, San Francisco 573 pp.

SOKAL, R. R. \& C. D. MichenER. 1958. A statistical method for evaluation systematic relationship. Univ. Kansas Sci. Bull. 38: 14091438. 
Fortran 90 program to calculate $\mathrm{D}$ and $\mathrm{D}$ ' values. A tutorial is also presented. An executable file may be obtained by the email jcsenamaia@gmail.com. To run this program, the computer must have a Fortran language compiler, which can be downloaded freely the website: http://force.lepsch.com. (Force 2.0.9 + GNU Fortran (GFortran).

\section{TUTORIAL}

This tutorial shows step by step how to provide the requested informations the GDDL.F program.

Step by step way of using the program.

- "How many OTU's (species)?"

Number of OTU's of groups to be analysed.

- "Names of OTU's." / "Name of OTU “, J

- "Which character will be analysed?"

Name

- "How many statuses?"

- "Inform Status "

- "Species " / "STATUS code "

For esch species give the corresponding status code

- "You informed " / "Is it correct? $(0=$ no $)$ "

The programcnforms the digitalyzed and asks for confirmation. In the case of mistakes, give "zero" to correct.

- "CALCULATION RESULTS “ / "D =", "DL=", "G ="

The resuts will be given at "D" e "DL" and "G"

- "Will you analyse another character? YES $=1$ "

for addicional character write 1. Qualquer outro número encerra o

programa 


\section{PROGRAM GDDL.F}

1: Program Calculo GDDL

2: Implicit none

3: $\quad$ Real, Dimension $(100,100)::$ Mat

4: Real, Dimension(100) :: soma, somasta

5: $\quad$ Real :: G, D, DL, Rnusta, Rnuto

6: Integer :: N, I, J,K,L,M,nuto,icod, nusta, inf, prod

7: Integer :: Nova

8: $\quad$ Character(len=15), Dimension(100) :: nomuto, nomstatus

9: $\quad$ Character $($ len $=15)::$ nomcarac

10: 4 FORMAT(I3)

11: Print*, "How many UTOs are part of the analyzed group?"

12: $\quad \operatorname{Read}(*, 4)$ nuto

13: $\quad$ Do $J=1$, nuto

14: $\quad$ Print*, "UTO name (specie ?) =", J

15: $\quad \operatorname{Read}^{*}$, nomuto(J)

16: Print*

17: $\quad$ end Do

18: 7 Print* ; Print*

19: 10 Do $30 \mathrm{~J}=1,100$

20: $\quad$ Do $20 \mathrm{~K}=1,100$

21: $\quad \operatorname{Mat}(\mathrm{J}, \mathrm{K})=0$

22: 20 Continue

23: 30 Continue

24: $\quad$ nomcarac $=$ " "

25: $\quad$ nusta $=0$

26: $\quad$ Do $L=1,100$

27: $\operatorname{nomstatus}(\mathrm{L})=$ " " 
28: $\quad$ End Do

29: Print*, "Character to be analyzed"

30: $\operatorname{Read}(*, 36)$ NOMCARAC

31: 36 Format(A15)

32: $\quad$ Print* ; Print*

33: Print*, "How many status does this character have?"

34: $\quad$ Read*, nusta

35: $\quad$ Print*

36: $\quad$ Print*

37: $\quad$ Do $\mathrm{K}=1$, nusta

38: $\quad$ Print*

39: $\quad$ Print*,"What is the STATUS associated with the code", $\mathrm{K}$

40: $\quad \operatorname{Read}^{*}$, NOMSTATUS(k)

41: $\quad$ Print*

42: $\quad$ End Do

43: $\quad$ Print* ${ }^{*}$ Print*

44: $\quad$ Do $\mathrm{J}=1$, nuto

45: 40 Print*,"Status code of *",NOMCARAC,"*for OTU = *", NOMUTO(J),"*"

46: $\quad$ Read $^{*}, \mathrm{icod}$

47: $\quad$ Mat $($ icod, $\mathrm{J})=1$

48: Print*, "You informed *", nomstatus(icod), "*"

49: Print*,"Is this correct? $0=$ NO /// $1=$ YES"

50: $\quad \operatorname{Read}^{*}$, inf

51: $\quad$ Print*

52: $\quad$ IF (inf $==0)$ GOTO 40

53: $\quad$ End Do

54: $\quad$ Do $k=1$,nuto

55: $\quad \operatorname{Soma}(\mathrm{K})=0$

56: $\quad$ End Do

57: $\quad$ Do $\mathrm{J}=1$, nuto

58: $\quad$ Do $\mathrm{I}=1$, nusta

59: $\quad \operatorname{Soma}(\mathrm{J})=\operatorname{Soma}(\mathrm{J})+\operatorname{Mat}(\mathrm{I}, \mathrm{J})$

60: $\quad$ End Do

61: End Do

62: Do $\mathrm{K}=1$, nuto

63: If (soma(K) .NE. 1) GOTO 50

64: $\quad$ End do

65: $\quad$ GOTO 60 
66: 50 Print*, "Xxxxxxxxxxxxxxxxxxxxxxxxxxxxxxxxxxxxxxxx"

67: $\quad$ Print*, "Error typing codes. Start over!!!"

68: $\quad$ Goto 7

69: 60 Do $K=1$, nusta

70: $\quad \operatorname{somasta}(\mathrm{k})=0$

71: $\quad$ End Do

72: $\quad$ Do I=1,nusta

73: $\quad$ Do $\mathrm{J}=1$, nuto

74: $\quad \operatorname{somasta}(\mathrm{I})=\operatorname{somasta}(\mathrm{I})+\operatorname{Mat}(\mathrm{I}, \mathrm{J})$

75: $\quad$ End Do

76: $\quad$ End Do

77: $\quad$ DO J $=1$, NUSTA

78: $\quad \operatorname{IF}(\operatorname{somasta}(\mathrm{j}) . \mathrm{EQ} .0)$ then

79: $\quad$ goto50

80: $\quad$ End IF

81: $\quad$ End Do

82: $\quad$ Prod $=1$

83: $\quad$ Do $\mathrm{J}=1$, nusta

84: $\quad \operatorname{Prod}=\operatorname{Prod} * \operatorname{somasta}(\mathrm{J})$

85: $\quad$ End Do

86: $\quad$ Rnusta $=$ nusta

87: $\quad$ Rnuto $=$ nuto

88: $\quad \mathrm{G}=$ Prod $* *(1 /$ Rnusta $)$

89: $\quad \mathrm{D}=5 *$ (Rnuto $-2 * \mathrm{G}) /($ Rnuto -2$)$

90: $\quad \mathrm{DL}=5-\mathrm{D}$

91: $\quad$ Print*

92: Print*,"RESULT OF CALCULATIONS"

93: Print*

94: Print*, "D =", D, "DL =", DL, "G =", G

95: $\quad$ Print*

96: Print*,"Do you want to analyze another character? $\mathrm{NO}=0$ // YES=1"

97: Print*

98: $\quad$ Read*, Nova

99: $\quad$ IF (Nova .EQ.1) goto 10

100: $\quad$ Print*

101: END Program

Recebido em 13 de março de 2021. 
